\title{
The Significance of the Ethnic Minority’s Trilingual Education Against the Globalization Background
}

\author{
LI Qiang \\ Yunnan Nationalities University, Kunming, China
}

\begin{abstract}
China is one of the multi-ethnic countries in the world. It is common for the people in the ethnic areas are using two or more different languages in their social communication. This paper discusses the characteristics and regulations of the trilingual education of the Chinese indigenous people as well as the significance of the ethnic minority's trilingual education against the globalization background from the perspective of socio-linguistics.
\end{abstract}

Keywords: indigenous people, trilingual education, globalization background

\section{Introduction}

Nowadays our human-beings are living in the multi-ethnic groups with multi-languages society under the globalization background. We get to know that different ethic groups employ their own language to communicate with their group members. Besides their internal communication, each group has to learn one more other languages so as to meet their need of self-development and self-survival. So, the multi-languages contact among the ethnic groups make the global economic and culture exchange frequently. We can clearly figure out the similarities and differences of the ethnic cultures by making the study of their languages. Moreover, we can interpret the reasons why the ethnic culture might have great changes from generation to generation. What we have done in this field can better help us to create conditions to renew and regenerate the inter-national relations formed in history and achieve the great unity and harmony of the world.

It is commonly believed that when a person learns a new language as a second or a third language, he or she would not avoid the interference of his first language more or less in the aspects of phonetic, syntax, and lexicon. So we may coin the term as "language transfer". This term can reasonably explain the language reorganization, the path of language transfer, and the development mechanism of meta-linguistic awareness, which includes phonological awareness, lexical awareness, syntactic consciousness, pragmatic consciousness, and so on in the process of third language acquisition of the third language learners. Take the Yi people (one of the ethnic groups in Yunnan province) as an example, most Yi children are growing up in the bilingual environment (the Yi language is their mother tongue or the first language, the mandarin Chinese is their second language), they begin to learn English as their third language or as a foreign language when they start their mid-primary program. Many related studies have shown that the third language acquisition is closely related to the second language acquisition; meanwhile there are also a great of differences between them, especially in the non-linearity, complexity,

LI Qiang, Ph.D., Professor, Foreign Language School, Yunnan Nationalities University, Kunming, Yunnan, P.R. China. 
acquisition process diversity, cognitive models, and so on. In most cases, the connotation of second language acquisition cannot reflect the characteristics of the third language learning. As a matter of fact, during the process of the third language learning, the third language will be, more or less, interfered and influenced by the mother tongue and the second language in pronunciation, vocabulary, and syntax. At the same time, the inter-language will be influenced by the third language (target language) in the same way. Therefore, in the practice of ethnic minority foreign language teaching, we should pay special attention to the combination of languages, the direction of language transfer, and the mechanism of contrastive interpretation.

\section{The Trilingual Education for the Ethnic Students}

Language is a tool for the communication and the exchange of thoughts and feelings among people who share the common cultural traditions and common social life with each other. Also language is a symbolic system that conveys feelings, the abstract of reality, the external form of ideas, and the emotion generated by the contact between nature and social things expressed by human beings.

Most languages in the world have their own-given grammatical categories. Grammatical category refers to the generalization of grammatical meaning expressed by the grammatical forms of words, and different languages have different grammatical meanings. Grammatical forms are varied. The grammatical forms and grammatical meanings of English verbs reflect the differences of tenses mainly through the consistency of the morphological changes of the words themselves and the relatively fixed phrase collocations used to express the tense difference.

Yi group is one of the ethnic minorities living in the southwest of China with a population of about four million. For the Yi students, the mother tongue or the first language is the Yi, the second language is the mandarin Chinese, and the third language is the English or some other foreign languages. After many years of teaching practice and research, we have found that contrastive translation teaching instruction is an efficient approach helping the Yi students' English grammar acquisition. For instance, the Yi language expresses the difference of tense dominated by "the subject", that is, different time auxiliary presented at the end of a sentence. In the sense of grammatical concept, the English and the Yi have four different timing representations: past, present, complete, and future. The most obvious difference point appears in their grammatical form. There are many difficulties in the cognition and understanding of grammatical conceptual meaning in learning the English tense, so the theory of trilingual education has its ideal application value in the practice of the English grammar teaching for the ethnic minority students. The practice of foreign language teaching for many years has proved that contrastive translation teaching instruction is an effective approach. For example, a contrastive translation approach can be used in teaching the four tenses which are commonly presented in the English language.

(1) The past tense: It is used to represent the actions that occurred in the past.

For example:

The English language: $\mathrm{He}$

$$
\mathrm{S}
$$

had

V

( past tense) the meal

$\mathrm{O}$ 


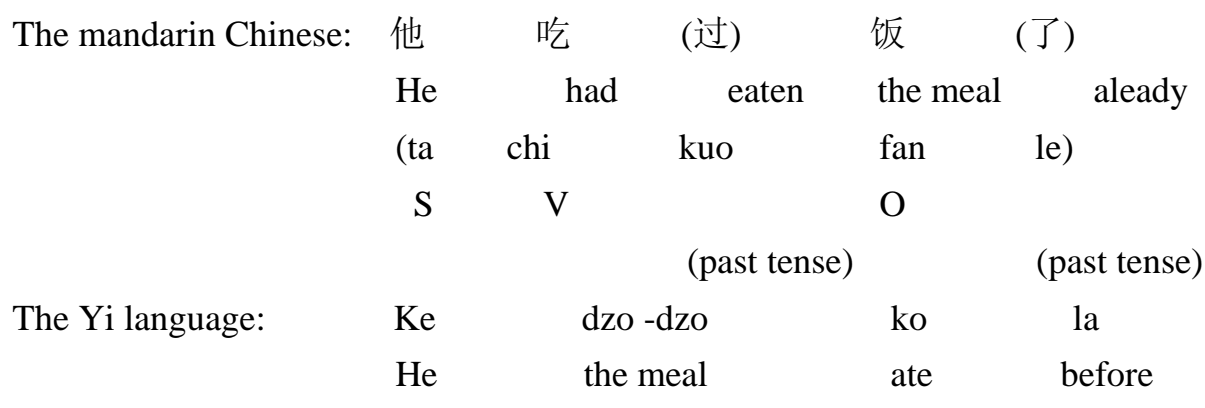

(past tense)

From the comparison of the syntactic tense structure between the three languages, the word order of the English and the Chinese is relatively similar. And the word order of the Yi language is obviously different from that of the English and the Chinese. When we try to use the English verb "have+" to express the action that has taken place in the past, we produce internal inflection in the lexical form and it becomes "had" to denote the behavior that occurred in a certain interval in the past whereas the Yi language is expressed by adding time auxiliary, such as "ko" or "la" in the end of the sentence.

(2) The present continuous: It is used to represent the actions that are taking place at present or now.

For example:

The English language: $\quad \mathrm{I}$ am reading the book

\begin{tabular}{lcccc} 
& \multicolumn{5}{c}{ (-ing, present continuous) } \\
The mandarin Chinese: & 我 & 正在 & 看 & 书 \\
& (wo & zhengzai & kan & shu) \\
& $\mathrm{S}$ & & $\mathrm{V}$ & $\mathrm{O}$ \\
The Yi Language: & $\mathrm{Ku}$ & su & sa & ze \\
& $\mathrm{I}$ & the book & am reading & now \\
(我 & 书 & 看 & 正在) \\
& $\mathrm{S}$ & $\mathrm{O}$ & $\mathrm{V}$ & (present continuous)
\end{tabular}

Through the comparison of syntactic elements, we can see that when the English verb "read" is used to express the action behavior that is taking place, we add the suffix "-ing” after the original form of the verb, and it becomes the present participle. To indicate what is happening or happening at the moment, the structure form is "be $+\mathrm{V}+$ ing". According to the single and complex number of the subject, the corresponding form of the relative verb is added before the present participle. However, the Yi language is expressed by adding a fixed time auxiliary "ze" at the end of the sentence.

(3) The present perfect tense: It is used to represent the action that have been completed.

For example:

The English language: He has done his own work

S V (the modifier) O




$\begin{array}{cccccc}\text { The mandarin Chinese: } & \text { 他 } & \text { 已经做完 } & \text { 自己的 } & \text { 事情 } \\ & \text { (ta } & \text { yi-jing zuo wan } & \text { zhijide } & \text { shiqing) } \\ & \mathrm{S} & \mathrm{V} & \text { (the modifier) } & \mathrm{O}\end{array}$

The Yi language: Khe ne mu ke wa.

He work done his own has

(他事情做他自己的完成)

S O V (the modifier) already

In expressing a completed action, the English verb changes in shape, the verb "do" has its internal inflection change to "done" which means an action that has occurred in a certain interval in the past and completed up to now. Its form of expression is: the fixed collocation of the auxiliary verb "have" or the third-person singular "has" plus the verb, "has+ V-ed (the past participle)" or a particular form of variation. But the Yi language is expressed by adding the fixed time auxiliary word "wa" at the end of the sentence.

(4) The simple future tense: It is used to represent the actions that will occur in the future.

For example:

\begin{tabular}{|c|c|c|c|}
\hline \multirow[b]{2}{*}{ The mandarin Chinese: } & S & \multicolumn{2}{|c|}{ (time auxiliary) } \\
\hline & 他 & \multirow{2}{*}{$\begin{array}{l}\text { 很快 (soon) } \\
\text { (time auxiliary) }\end{array}$} & 就要走(去) \\
\hline & $\mathrm{S}$ & & V \\
\hline \multirow[t]{4}{*}{ The Yi language: } & Khe & $\mathrm{pu}$ & ga ka \\
\hline & $\mathrm{He}$ & go & will/ be going to \\
\hline & （他 & 走 & 准备/打算) \\
\hline & S & (tir & (time auxiliary) \\
\hline
\end{tabular}

From the above three languages' comparison, on the one hand, we can see that the English language and the mandarin Chinese are the same word-order in most cases. In other words, when an adverb modifies a verb, the English adverb can be placed either front or back of the verb; the mandarin Chinese commonly placed before the verb; the Yi language only can be placed in the back of the verb. So, we may figure out that the syntactic difference between the English and the mandarin is not huger than that of the English and the Yi language as well as the mandarin and the Yi language. Presumably the syntactic feature of the Yi language is a little bit like the Japanese language. On the other hand, when both of the mandarin and the English verbs "go" are used to express the action or behavior of the future, it achieves through the modal verb "will" and the original form of the verb "will + V + original" whereas the Yi language is used to express by adding the tense auxiliary "ga" after the verb and the modal auxiliary "ka" at the end of the sentence.

By comparing the four tenses with the three languages, it shows that different ethnic groups' thinking habits and language expressions are different from each other because of the historical and cultural inheritance patterns and the spatial and temporal differences in different regions. Therefore, it is important to make the study of and learn the language characteristics and the way of national culture inheritance of different ethnic groups plays a positive and irreplaceable role in analyzing the characteristics and the rules of language education of different nationalities, and in engaging in foreign language teaching of ethnic minorities. This is also an important prerequisite for the application of contrastive translation approach. 


\section{The Implication From the Ethnic Minority's Trilingual Education}

There are great differences in language thinking modes among different ethnic groups, and these differences can be understood to some degree as the different thinking characteristics of each group. Therefore, in the actual teaching process, we should focus on the learning of the sentence components and word order of the English through the teaching contents, so that the Yi students can understand how the English people express their thoughts and feelings. The expression format of the English is similar to that of the mandarin in some degree; both of them similarly employ the grammatical relation of the subject-predicate-object, while the Yi language tends to employ the similar language expression format similar to that of the Japanese language as the subject-object-predicate grammatical relation.

From the above discussion, we may have the enlightenment that the ethnic minority's trilingual education is not only the language itself, but also the culture exchange. After making the study of the issue, we can find the efficient approach to improve the quality of the ethnic groups' trilingual education. The application of the contrastive translation approach is one of them. The main points of the approach are as follows:

Firstly, the word order is the core element in the basic unit of language, which is used to construct the rules of syntactic relation, verb-object relation, and limited relation of language, and the word order itself can convey meaning. Some sentences with the same conceptual meaning have different thematic meanings because of their different word order, and thus have different communicative value.

Secondly, sentence is the largest grammatical unit of language, which is used to express a relatively independent and complete pattern of thought and meaning. Through the comparison of sentence patterns, the Yi students can figure out that when the English verbs express the characteristics and states of the action behavior, they are mainly realized by the internal inflectional changes of the verbs, but the Yi verbs themselves remain unchanged. It is mainly reflected by adding different time auxiliary words at the end of sentence.

Thirdly, combined with the word order characteristics of sentence expression in the English, the mandarin, and the Yi languages, we can analyze and summarize the characteristics and rules of the English tense in order to achieve the purpose of consolidation and application of teaching, and we train them by specialized translation and interpretation training.

In addition, it is also very important for the Yi students to learn and recognize the language characteristics of different nationalities through the innovation of teaching content and teaching methods. The Yi people have been used to concrete and visual thinking for a long time, while the English people are used to abstract and indirect logical thinking. Different peoples in the world have different natural environments, different social environments, and the different history and landforms, so they are different in cognitive ways and behaviors to the objective things. The obvious differences in linguistic level contain the national characteristics of thinking and show distinct national cultural characteristics. There are obvious differences in the chase of things, behaviors, and values in different ethnic social and cultural circles. This difference is the national character of thinking reflected in language characteristics. The English nation lives in a relatively open social and cultural environment, and a great deal of cultural information stimulates the metabolism of things and promotes the rapid development of the English language, which is the economic pattern of mechanized production and industrialization and commercialization. The adaptation of the English language and culture is oriented towards extroversion. 
However, Yi people live in a relatively closed social circle of economy and culture for a long time. Foreign culture and modern information are difficult to touch the transformation of national society. The inheritance of Yi nationality's history and culture and the metabolic process of the surrounding things are relatively slow. It makes the thinking association and concept meaning of Yi language words relatively limited, and the adaptability of Yi language and culture develops towards the direction of internal circulation. The expression pattern of the language thinking of the Yi language is: behavior subject—behavior object—behavior sign—behavior. The language communication way is: subject + object + adverbial + verb predicate. The sentence component of this kind of language expression mode is relatively fixed in the position of words in order and the change of word order is not flexible enough.

\section{Conclusion}

Language is not only an important tool for human communication, but also a tool for thinking. The process of human thinking is the cognition and reflection of the objective material world by the human brain through language. Then he can form the concept. When he posses what kind of thinking mode, he will have what kind of behavior consciousness; when he achieves what kind of behavior way, then he will output what kind of behavior. A real world is largely based on group language habits, because language itself is a self-contained system of symbols that adds meaning to experience. It presupposes some interpretation of the real world by human consciousness. The language of any nation in the world bears the psychology and thinking habits of the nation and records the historical culture of the nation and the continuous ideological consciousness in the national social life. At the same time, it regulates the understanding of the objective material world and the explanation of all phenomena around it.

\section{References}

Li, Q. (2003). The cultural diversity and English teaching approaches. Beijing: The Social Science of China Press.

Wang, F. X. (1994). Culture and language. Beijing: The Foreign Language Teaching Press.

Yang, G. Y. (1997). The selected works on the ethnic languages and literature of Yunnan. Kunming: Yunnan Ethnic Group Press. Yu, L. S. (1983). The figure of speech comparison of the English and the mandarin. Beijing: The Commercial Publishing House. Zhang, T. Z. (1978). Teaching English—A linguistic approach. London, Richard Clay: The Chaucer Press Ltd. Zhang, T. Z. (1983). The practical English grammar. Beijing: The Commercial Publishing House. 